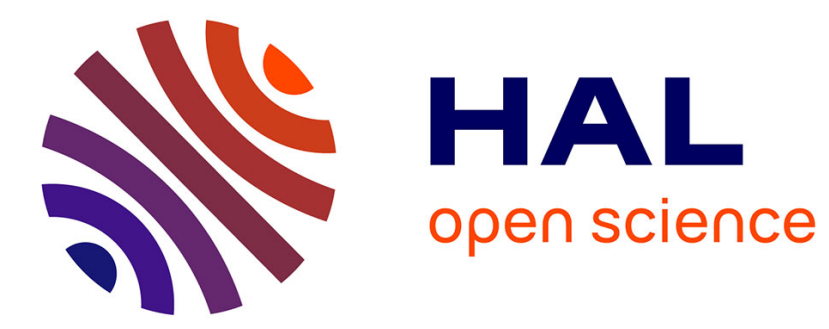

\title{
AN IMPROVED FULLY CMOS COMPATIBLE BIPOLAR STRUCTURE
}

\author{
A. Gérodolle, G. Giroult, S. Martin, A. Nouailhat
}

\section{To cite this version:}

A. Gérodolle, G. Giroult, S. Martin, A. Nouailhat. AN IMPROVED FULLY CMOS COMPATIBLE BIPOLAR STRUCTURE. Journal de Physique Colloques, 1988, 49 (C4), pp.C4-93-C4-96. 10.1051/jphyscol:1988419 . jpa-00227917

\section{HAL Id: jpa-00227917 https://hal.science/jpa-00227917}

Submitted on 1 Jan 1988

HAL is a multi-disciplinary open access archive for the deposit and dissemination of scientific research documents, whether they are published or not. The documents may come from teaching and research institutions in France or abroad, or from public or private research centers.
L'archive ouverte pluridisciplinaire HAL, est destinée au dépôt et à la diffusion de documents scientifiques de niveau recherche, publiés ou non, émanant des établissements d'enseignement et de recherche français ou étrangers, des laboratoires publics ou privés. 
AN IMPROVED FULLY CMOS COMPATIBLE BIPOLAR STRUCTURE

\author{
A. GÉRODOLLE, G. GIROULT, S. MARTIN and A. NOUAILHAT \\ CNET/CNS, BP 98, Chemin du Vieux Chêne, F-38243 Meylan Cedex, France
}

\begin{abstract}
Résumé - Une technologie bipolaire compatible CMOS étudiée au CNET a été simulée par le programme TITAN 5. Pour diminuer la résistance collecteur, une méthode incluant la formation de tranchées à fond perméable a été imaginée. La simulation process permet d'étudier l'intérêt d'une telle technique.
\end{abstract}

Abstract - A fully CMOS compatible bipolar technology is studied. 2-D process simulations of the device have been carried out before wafer processing; comparisons of the results with experiments are presented. A new idea for making the collector, without standard epitaxy of a highly doped buried layer, is described. The 2-D simulation results enable the advantages to be checked with regard to the classical approach.

\title{
1- INTRODUCTION
}

To decrease the collector access resistance in BICMOS technology, the classical techniques are to form a buried collector by epitaxy, or to make a highly doped "retrograde well" with high energy and dose implant $/ 1$. This latter technique could be used in CMos technology, but it requires high dose and energy machines and is sensitive to certain mask problems.

The alternative idea presented here is to use trenches (filled with highly doped polysilicon) as the collector contact as well as additional dopant source for the collector, acting as a buried layer. This technique has the advantage of not needing any additional thermal or ionic implant step. The only additional steps, which come just after the formation of the locos and implantation of the retrograde well, are the formation, oxidation and polysilicon filling of the trenches. This technique is fully CMOS compatible, and avoids selective epitaxy for the buried layer of the collector. But, of course this is not simple to achieve. Process simulation of this structure has been performed, in order to validate the theoretical interest of this technology. Different values have been tested for the doping concentration and trench depth.

\section{2- PRESENTATION DF BICMOS MAIN STEPS}

The process flow is the same as in the 1 micron CMOS technology developed at the CNET, with only one additional mask level. The bipolar transistor process steps are those of the Nwell PMOS transistor, except for one additional ionic implant of boron to adjust the intrinsic base and the gate oxide etching before polysilicon deposition. These two process steps use the same mask.

The main features are the following : the gate arsenic-doped polycide acts as the emitter contact and as a doping source for the emitter. After polycide etching, a lightly doped extrinsic base region (LDEB) is implanted before deposition of the oxide-sidewall, to reduce the base resistance ( $\mathrm{Rbb}$ '). $5 \mathrm{SO}_{2}$ spacers ( $0.3 \mathrm{microns}$ wide) are used for the self-alignment of the extrinsic base. The drive in of the emitter and the dopants activation are obtained during the final RTA. Note that, without the additional implantation of the intrinsic base, a very shallow base can be abtained, resulting from the diffusion of the boron which has been implanted into the silicide at the extrinsic base implantation step. The $\mathrm{N}$ well acts as the collector. In order to improve the performances of the bipolar and the resistance to the latch-up of the cM0S devices, a retrograde well is used. 


\section{3- SIMULATION}

The process simulations of the transistor have been performed using the TITAN-5 program, which allows multi-mayer ionic implantation and diffusion to be simulated. This helped to choose the energy and dose of the additional base implant. Profile calculations are made in polycide and silicon; values of the segregation coefficient and diffusivity have been chosen in accordance to $/ 2 /$ and the results are in good agreement with SIMS and electrical measurements (Figure 1 ). A complete study of arsenic and boron codiffusion in the three layers WSix, polysilicon, silicon is to be published in the near future.

Simulation of the complete structure, including the collector contact, can be provided, using a very sharp meshing in the active area (Figure 2 ).

\section{4- SIMULATION OF AN IMPROVED BIPOLAR TRANSISTOR : A BURIED DIFFUSED COLLECTOR}

The structure simulated is shown in Figure 3. The trenches are formed after the locos formation, in the same way as insulation trenches; they are then slightly oxidized, and the oxide and the silicon are etched anisotropically, so that the trench becomes permeable to the dopant species. The trenches are then filled with highly doped polysilicon (Phosphorus, $10^{20}$ to $3.10^{20}$ atoms $/ \mathrm{cm}^{3}$ ). During the thermal annealing used for the retrograde well (150 mn, $1050^{\circ} \mathrm{C}$ ), the dopant diffuses in the silicon, making a zone equivalent to the collector buried layer of the epitaxial technology. The simulations have been made on a 4 micron wide structure. Three simulations have been carried out with a $1.6 \mu \mathrm{m}$ wide and $2.2 \mu \mathrm{m}$ deep trench, with a phosphorus concentration from $10^{20}$ to $3.10^{20}$ atoms $/ \mathrm{cm}^{3}$. At each time, the square resistance of the collector has been calculated for several cross-sections (Figure 4).

With $10^{20}$, the square resistance remains $1.2 \mathrm{k} \Omega$ from $X=3 \mu \mathrm{m}$ to $4 \mu \mathrm{m}$. To obtain a resistance of $100 \Omega$ the position should be at $X=2 \mu \mathrm{m}$, which means that the dimensions have to be reduced by $2 \mu \mathrm{m}$, which is not feasible.

With $2.10^{20}$, the resistance is $1.2 \mathrm{k} \Omega$ at $X=4 \mu \mathrm{m}, 393 \Omega$ at $X=3 \mu \mathrm{m}$. This means that reducing the dimensions by only $l \mu$ is sufficient to obtain a real improvement in the resistance.

With $3.10^{20}$, the resistance is $973 \Omega$ at $X=4 \mu \mathrm{m}, 80 \Omega$ at $X=3 \mu \mathrm{m}$. The collector access resistance value is low, but the highly doped collector area is too close to the base. To overcome this problem, another simulation with a deeper trench has been carried out. With a phosphorus concentration of $3.10^{20}$, and a $3 \mu \mathrm{m}$ deep trench (Figure 5), the transistor active area remains optimized, as expected. Moreover, the collector access resistance has been reduced : $43 \Omega$ at $X=3 \mu \mathrm{m}, 134 \Omega$ at $X=3.5 \mu \mathrm{m}, 435 \Omega$ at $X^{\prime}=4 \mu \mathrm{m}$. This is due to the fact that the total phosphorus dose in the polysilicon trench is higher, and therefore the phosphorus depletion of the trench is slower. At the end of the process, the remaining phosphorus concentration in the polysilicon is $2.10^{20}$ atoms $/ \mathrm{cm}^{3}$, instead of $1.5 .10^{20}$ with the $2 \mu \mathrm{m}$ deep trench.

\section{5- CONCLUSION}

A general 2-D simulator, which makes no assumption on the structure, can be used as a predictive tool, to validate new ideas, before starting the process itself. In this case a new technique for processing fully CMOS compatible bipolar transistors without epitaxy has been investigated. Simulations show that a very low collector access resistance can be obtained without disturbing the transistor behaviour, provided a $3 \mathrm{\mu m}$ deep trench, which is dopant permeable at the bottom and insulated at the sides, can be achieved. 


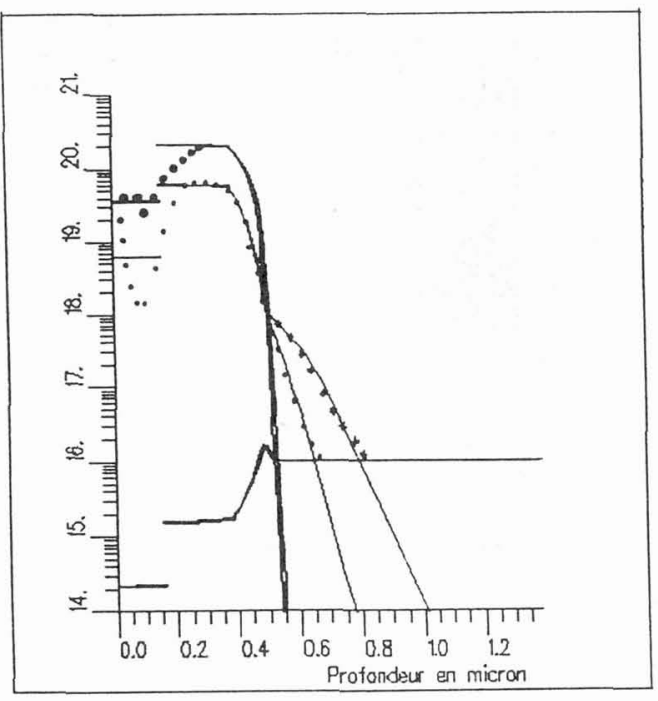

Fig. 1 - Intrinsic transistor area. Cross-section of $A s$ and B concentrations. SIMS measurements:

* B with boron adjustement implantation

- 8 without (the same as * in polycide)

- As in both cases

Simulation results

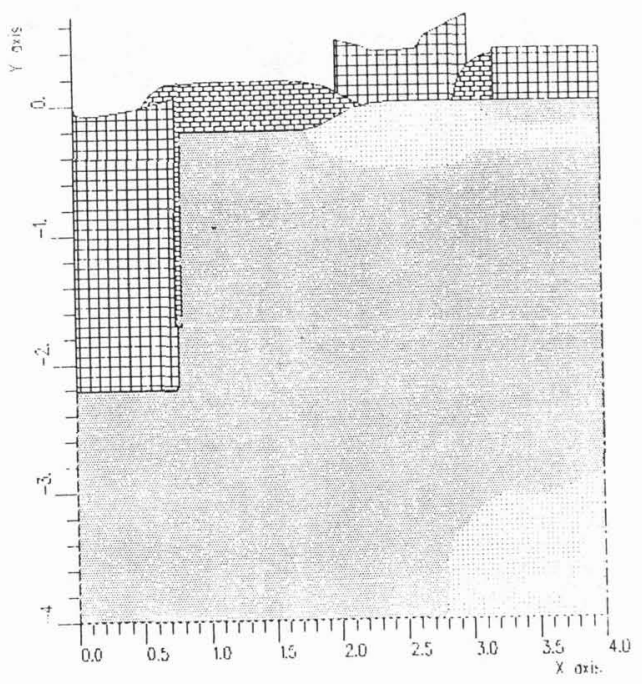

Fig. 3 -structure of the Bipolar $T$. The trench and emitter widths have to be divided by a factor 2 for the simulation. The real trench width is 1.6 microns.

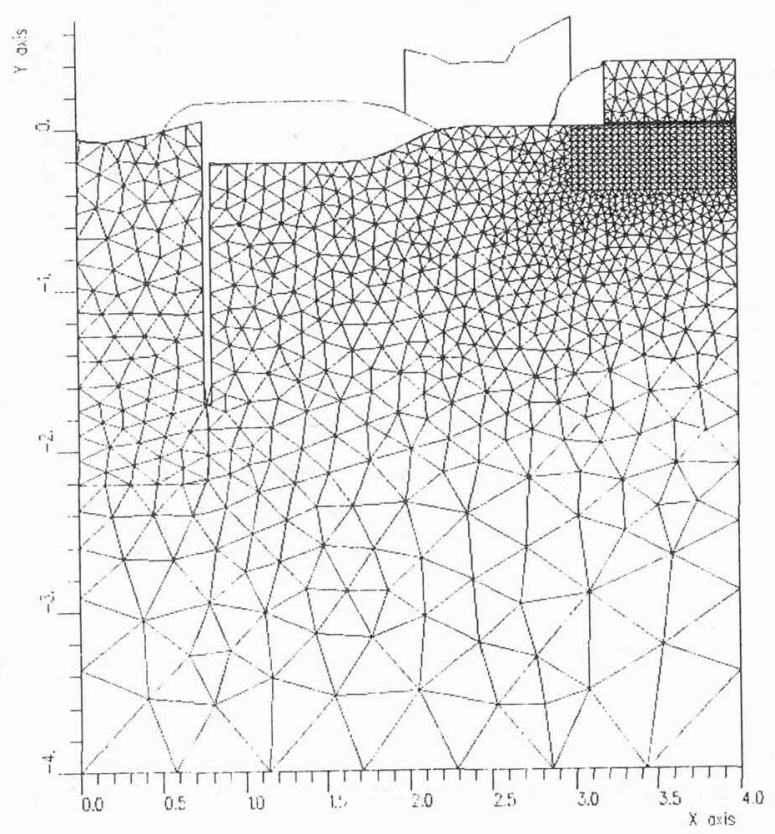

Fig. 2 -Exemple of meshing. 


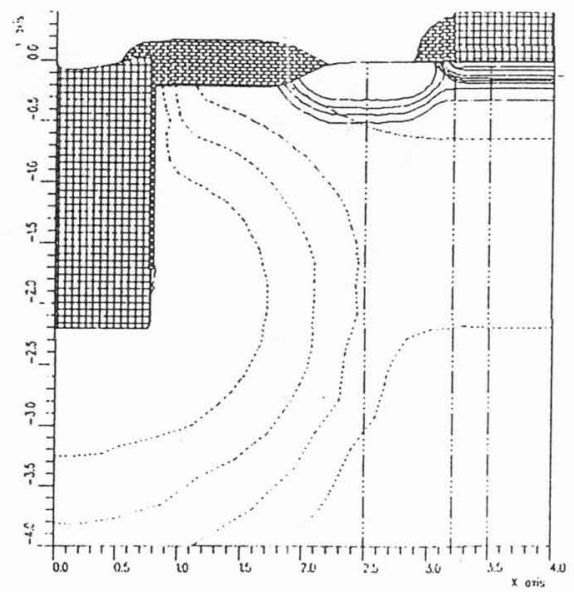

a

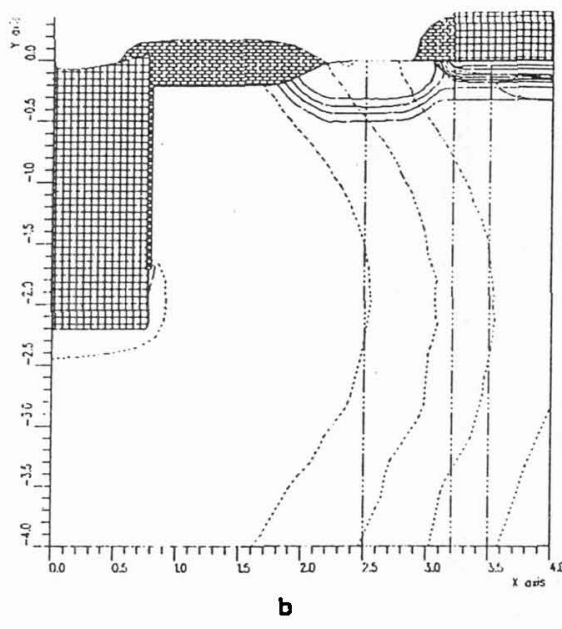

$20 \quad 20$

Fig. 4 -isoconcentrations of phosphorus corresponding to 10 (a) and 3.10 (b) atomes/cm 3

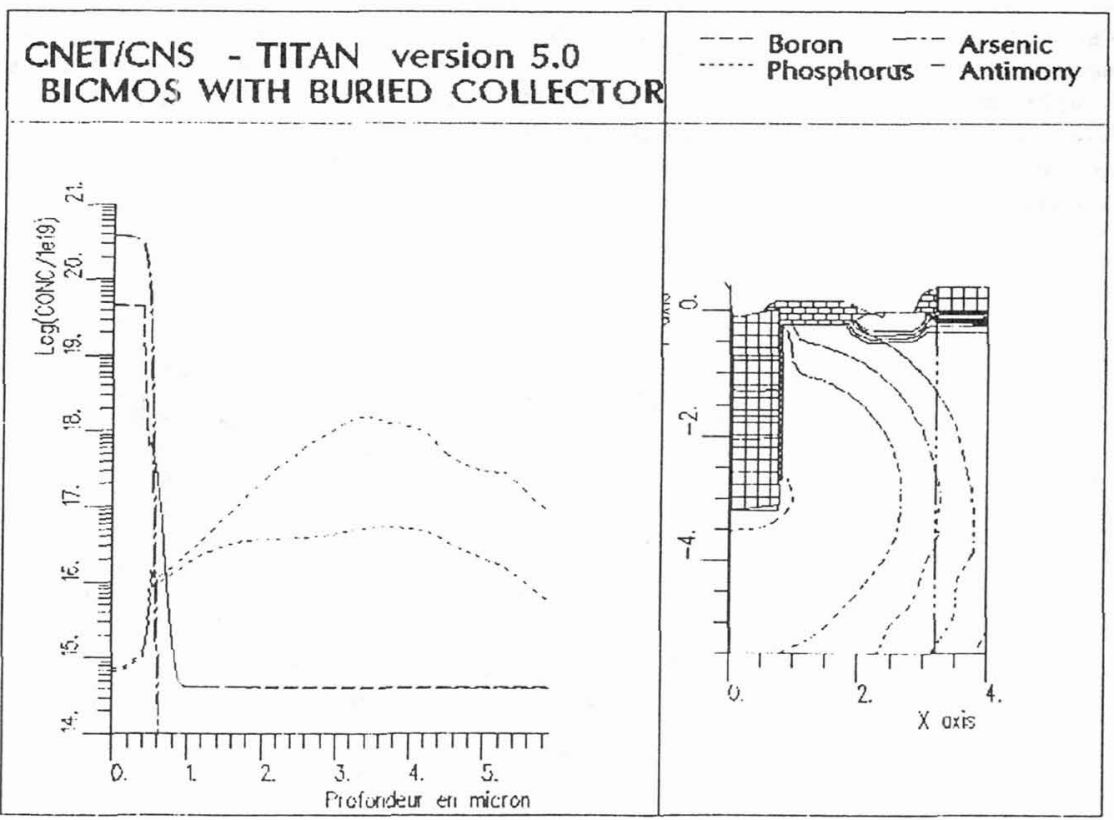

Fig. 5-cross-sections of the doping concentration at $X=3.2$ um and $X=4$ um

The authors would like to thank M. Gauneau (C.N.E.T. Lannion) for SIMS analysis. References

/1/ A.R. Alvarez, 'BICMOS technology', short course IEDM 1987

/2/ S.P.MURARKA, D.S. WILLIAMS, J.VAC.SCI.Technol.B, Vo15,NO6,Nov/Dec 1987 